\title{
Creating Awareness of Bullying, Its Impact on Children, and Strategies towards Behavioural Change
}

\author{
Wasiu Abayomi ${ }^{*}$, Angela Daniels ${ }^{2}$ \\ ${ }^{1}$ University of Technology, Jamaica \\ ${ }^{2}$ International University of the Caribbean, Jamaica \\ Email: ^abayomiw@yahoo.com
}

How to cite this paper: Abayomi, W., \& Daniels, A. (2021). Creating Awareness of Bullying, Its Impact on Children, and Strategies towards Behavioural Change. Open Journal of Social Sciences, 9, 363-394. https://doi.org/10.4236/jss.2021.911026

Received: September 1, 2021

Accepted: November 27, 2021

Published: November 30, 2021

Copyright () 2021 by author(s) and Scientific Research Publishing Inc. This work is licensed under the Creative Commons Attribution International License (CC BY 4.0).

http://creativecommons.org/licenses/by/4.0/ (c) (i) Open Access

\begin{abstract}
In Jamaica research conducted revealed that $70 \%$ of the participants reported being bullied with more girls than boys (PSearch Associates Company Ltd., 2015). The purpose of this research is to create awareness and identify strategies towards a change in attitude regarding bullying, by using workshops with grade seven students at an all-girls school in Kingston, Jamaica. Workshop is "an educational method" which "provides learners with an opportunity to exchange information, practice skills and receive feedback" (Steinert \& Ouellet, 2012: p. 3). The sample population consisted of four students and two Guidance Counsellors. Action Research methodology was used to decide whether or not workshops can be used to create awareness of bullying among grade seven students and determine to what extent can workshops increase awareness and change in attitude and behaviour towards bullying. Focus Group, and Qualitative approach using Questionnaires and Interviews were used to collect the data. The findings revealed that there was an increase in knowledge among the students in the areas of their understanding of bullying, the reason behind children being bullied, the impact on the victim and strategies in addressing and preventing bullying.
\end{abstract}

\section{Keywords}

Bulling, Behavioural Change, Aggressive Behaviour, Action Research

\section{Introduction}

The phenomenon of bullying in schools is a universal malady which if not addressed successfully can result in a populace demonstrating psychological, emotional, physical and social dysfunctionality which can last for over a prolonged 
period. Literature is replete with the negative impact of bullying holistically on the individual that is being bullied irrespective of age, ethnic background or socio-economic level (Dunne et al., 2013; Barnes et al., 2012; Side \& Johnson, 2014; Schneider et al., 2012; Hutchinson, 2012).

Bullying is a form of aggressive behavior that is carried out intentionally and repeatedly to harm another party who is physically or psychologically less powerful (Olweus, 2010 as cited in Mok et al., 2014). There are different types of bullying such as physical (hitting, kicking pushing), verbal (teasing, name calling), relational aggression (rumour spreading, exclusion, coercion), damage to property (taking lunches, destroying school books), cyberbullying (textmessage, email and social media harassment) (Migliaccio \& Raskauskas, 2013) and extortion (PSearch Associates Company Ltd., 2015). Bullying can occur at any location such as in the classroom, the playfield, school bathroom and the lunch area.

Ministry of Education in Jamaica (2008) is cognizant of the realities of the issues associated with bullying and seeks to tackle it through its inclusion within the Safety and Security manuals which have been distributed to school officials for its implementation. Despite the governmental input bullying remains an issue for Jamaica and so the Child Development Agency in Jamaica commissioned a study entitled Investigating the Prevalence and Impact of Peer Abuse (Bullying) on the Development of Jamaica's Children with the goal of "...the reduction of incidences of bullying within the education system...” (Child Development Agency, 2015). The said report indicated that bullying in Jamaica is an issue that is becoming a serious problem, that more girls are bullied than boys ( $66.9 \%$ of girls and $62.9 \%$ of boys) and that there is a concensus by stakeholders that there is the need of an effective immediate response (PSearch Associates Company Ltd., 2015).

The government of Jamaica has as one of its mandates to educate the populace to inter alia, occupy positions of influences locally and globally therefore there is the need for a healthy school environment where the student feels safe, nurtured and there is mutual respect within the school community (Ministry of Education, 2008). The researchers have a profound interest in the welfare of our nations' children and seek to hopefully assist in creating a positive change in their attitude and behaviour through creating awareness of bullying, its impact and strategies.

The research focus on the area of creating awareness of bullying, its impact on children, and strategies towards behavioural change, among secondary level students. And Identifying Strategies towards a change in attitude regarding bullying, among grade 7 students at an all girls' school in Kingston, Jamaica.

\subsection{Purpose Statement}

The purpose of this research is to create awareness and identify strategies towards a change in attitude regarding bullying, among grade seven students by 
using workshops.

\subsection{Research Questions}

1) How can workshops be used to create awareness on bullying among grades 7 students?

2) To what extent can workshops increase awareness and change in attitude and behaviour towards bullying?

\subsection{Significance of the Research}

Bullying affects children of all ages, ethnic background and socioeconomic levels. "Bullying can threaten students' physical and emotional safety at school and can negatively impact their ability to learn" (Stopbullying.gov, n.d.). There is the need to develop a deeper understanding of the problem and possible interventions towards its treatment and or prevention. There is therefore the need for change in the students' attitude and behaviour. Bullying is a form of aggressive behavior that is carried out intentionally and repeatedly to harm another party who is physically or psychologically less powerful (Olweus, 2010 as cited Mok et al., 2014). Literature has not indicated the use of workshops in schools in Jamaica among girls in grade 7 . The findings can add to the existing literature another medium for addressing bullying within schools.

\subsection{Limitations}

Although the research participants were enthusiastic to participate in the research the extent to which the research could have been conducted was limited because of the time when the researcher gained access, which was in the final term of the academic year when the students were preparing for their end of term examinations.

\subsection{Delimitations}

This research was conducted with only the girls who volunteered from the grade 7 classes and the 2 Guidance Counsellors who volunteered to participate from the selected all-girls school in Kingston, Jamaica. The goal of this research is to create awareness and identify strategies towards a change in attitude regarding bullying, by using workshops. The results from this study though may be useful, is not generalizable.

\section{Literature Review}

The review of existing literature is fundamental to realising the goal of this research as such the themes bullying in secondary schools, government articles on bullying, stakeholders' view on bullying, the effect of bullying on students, other approaches to creating awareness of, and addressing bullying, and using workshops in creating awareness of bullying towards a change in attitude and behaviour are selected as indicated in Figure 1 below. 


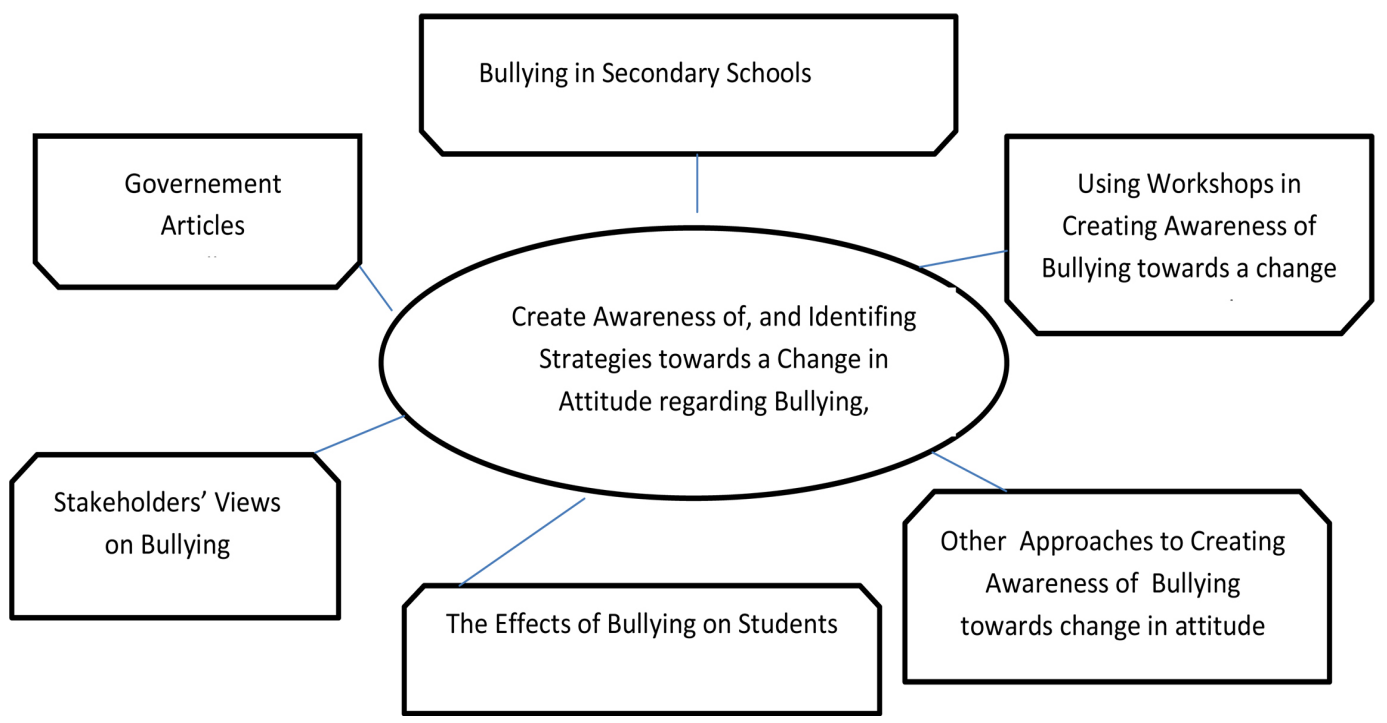

Figure 1. Concept mapping on literature review.

\subsection{Bullying in Secondary Schools}

Bullying is a ubiquitous issue in our schools irrespective of geographical location, race or gender; and the victims are affected negatively psychologically, emotionally, physically, socially and academically (Yerlikaya, 2014; Gibson-Young et al., 2014; Arslan et al., 2012; Perkins et al., 2014). Bullying penetration occurs in the United States of America among middle school students (Perkins et al., 2014; Gibson-Young et al., 2014; Allen, 2012), Turkey among students from grades five to seven (Arslan et al., 2012; Yerlikaya, 2014), China among students within elementary through to high schools (Huang et al., 2013; Mok et al., 2014), Australia with students from elementary through to high schools (Hemphill et al., 2012; Lester et al., 2012) and in Ghana among students from senior high schools (Dunne et al., 2013). These students experience diverse types of bullying such as verbal, physical, relational, social (Hemphill et al., 2012; Perkins et al., 2014; Dunne et al., 2013; Migliaccio \& Raskauskas, 2013; Allen, 2012; Gibson-Young et al., 2014; Ockerman et al., 2014).

\subsection{Government Articles on Bullying}

The government of Jamaica has recognized the utmost importance of addressing the issues of bullying and this is evident in the call for its inclusion within the Safety and Security guidelines towards a school environment that engenders a "safe and secure zone" (Ministry of Education, 2008) for students of diverse beliefs, culture, social class, socioeconomic status and geographical location.

One of the governmental stakeholders, the Child Development Agency through its intimate involvement with children commissioned a research titled "Investigating the prevalence and Impact of Peer Abuse (Bullying) on the development of Jamaica's children". As stated by the Manager for Research and Development Mr. Randell Baliey, the major goal of the study is to "contribute to 
the reduction of incidences of bullying within the education system..." (Child Development Agency, 2015).

\subsection{Stakeholders' Views on Bullying}

Students presented diverse perspectives on bullying such as offenders bully because they desire power and or status and that the offenders themselves have unresolved issues, also that the victims are viewed as odd or different (Thornberg, 2015; Side \& Johnson, 2014). Teachers shared the views that cyberbullying results in leaving a "long-lasting negative effect on students" (Stauffer et al., 2012: p. 359). Representatives from The Children National Medical Centre and the Institute for Psychiatric Research both located in the United States of America articulated that "bullying is a major public health problem that demands the concerted and coordinated time and attention of health-care providers, policy-makers and families" (Srabstein \& Leventhal, 2010). Hutchinson (2012) suggests that teachers felt that students would view verbal bullying as the "most upsetting victimization" (Hutchinson, 2012: p. 36).

\subsection{The Effects of Bullying on Students}

The bullied are impacted negatively and their subjective psychological processing determines their position and how they are viewed by others (Side \& Johnson, 2014). The victims are "teased, called hurtful names, physically abused, excluded from groups to hurt their feelings, belongings taken and sometimes damaged, threaten to hurt and negative rumours spread" (Perkins et al., 2014: p. 810; Ockerman et al., 2014; Migliaccio \& Raskauskas, 2013; Colibaba et al., 2012). The victims experience decline in their academic performance (Arslan et al., 2012; Yerlikaya, 2014), diverse psychoemotional, social issues and medical issues (Arslan et al., 2012; Gibson-Young et al., 2014; Yerlikaya, 2014; Side \& Johnson, 2014) and truancy (Dunne et al., 2013; Schneider et al., 2012). The students from lower grades are said to be targeted for bullying more than those from the higher grades (Schneider et al., 2012). It is therefore imperative for aholistic approach including students, teachers, school principals, experts (Counsellors, Psychologists etc.), key policy makers, police and School Inspectors (Colibaba et al., 2012), education and training, to minimize or prevent bullying (Pugh \& Chitiyo, 2012).

\subsection{Other Approaches in Creating Awareness of Bullying towards Change in Attitude}

Bullying as the extant literature informs affects negatively both the offender and the victim and as such it behooves the stakeholders, more so the students, to discover effective approaches so that this issue can be addressed when the appropriate intervention is implemented. Consequently, writers seek to identify the various methods that can be utilized with the view of addressing this issue. Migliaccio \& Raskauskas (2013) employed the "video-discussion model to increase the students awareness of bullying, a curricula (Jones \& Augustine, 2015; Smith 
et al., 2012) and shared concern approach as an anti-bullying intervention (Wurf, 2012; Jones \& Augustine, 2015; Rigby, 2014), small groups discussions facilitated by adults (Smith \& Smith, 2014). The quality circle approach (Smith et al., 2010), the zero tolerance model and the early intervention method (Roberge, 2012), direct sanctions, restorative practice mediation, support group method (Rigby, 2014), community-based programs (Holt et al., 2013).

\subsection{Using Workshops in Creating Awareness of Bullying towards Change in Attitude}

Steinert \& Ouellet (2012) defines workshop as "an educational method" which "provides learners with an opportunity to exchange information, practice skills and receive feedback" (p. 3). The writer further stated that workshops "can also be adapted to diverse settings in order to facilitate knowledge acquisition, attitudinal change or skill development" (p. 3).

The aforementioned literature indicates that diverse approaches have been employed in addressing the issue of bullying, both a reactive approach by focusing on intervention post bullying experience (Colibaba et al., 2012; Murray-Harvey et al., 2012; Grossi \& Santos, 2012) and proactive approach by implementing anti-bullying policies within the school's curriculum which would be a mitifaceted approach involving students, parents, teacher, principals, dean of disciplines, guidance and counsellors and the school's administrative personnel (Rigby, 2014; Jones \& Augustine, 2015). Other writers included workshops as a part of their intervention (Lucassen \& Burford, 2015; PSearch Associates Company Ltd., 2015); and recommend its inclusion in future research on bullying (Adeoye, 2013; PSearch Associates Company Ltd., 2015; Lucassen \& Burford, 2015).

The wealth of literature revealed that further research is necessary, Migliaccio \& Raskauskas (2013) argue that "as students gain awareness of bullying and the different types of bullying that occur they are better able to identify and intervene... (p. 78); PSearch Associates Company Ltd. (2015) promotes "raising awareness of issues and concepts related to bullying through ...sessions such as workshops (p. 5).

\subsection{Theoretical Framework}

"The proper reward is that we can now use what we have learned, can cross the barrier from learning into thinking" (Bruner, 2006: p. 25). Seminal literature informs that Jerome Bruner, one of the proponents of Constructivism Theory purports that "learners construct new ideas or concepts based upon existing knowledge" (Bruner, 1960). Constructivism, is a platform for students to learn through the transformation of information as they relate to the content experientially. The students from the selected girls' school would have had prior knowledge from prior experiences and their culture, consequently, enabling them to connect experientially with the material.

Jean Piaget Cognitive formal operational stage of Cognitive Development 
Theory which spans the ages 11 years to adulthood elucides that adolescents "reasons in more abstract, idealistic and logical ways" (Santrock, 2002: p. 37). According to the seminal literature of Inhelder and Piaget (1959) “...its most important features are the development of the ability to use hypothetical reasoning based on a logic of all possible combinations and to perform controlled experimentation" (p. xiii). The adolescent's ability to process logically, rationally and in abstract terms is foundational for experiential learning.

Cognitive Behavioural Rational Emotive Behaviour Theory created by Albert Ellis focuses on a change in thoughts with a resultant change in behaviour. Ellis and Dryden (1997) assert that beliefs "exert strong influences on" one's "cognitive, emotional, and behavioral consequences" (p. 9); and that "a person can change his or her behavior to effect inferential and/or philosophic change" ( $p$. 26). This therefore provided robust undergirding of providing the students with information on bullying its impact and strategies which can serve to change their belief on the subject towards positive change in their behaviour on the issue of bullying.

\section{Research Methodology}

\subsection{Research Design}

Action Research design which is a systematic procedure was utilized to collect and analyse data towards addressing practical problem (Creswell, 2012) is best suited for this research. Action research is a cyclic approach which involves in each cycle plan, act, observe and reflect. It is dynamic and can facilitate several cycles commencing each cycle with planning and terminating with reflection as illustrated in Figure 2 below. The researchers employed one cycle.

The Planning phase involves the identification of the issue and a plan of action with the view of improving the situation, the intervention is implemented in the Action phase, in the Observation phase there is systematic observation of the effects of the action and the Reflection phase comprises of reflection, evaluation and description of the effect of the action to determine what transpired and the next step (Burns, 2010).

Workshops were used to create awareness of bullying among girls in grades 7 at an all girls' school in Kingston, Jamaica. A Microsoft PowerPoint presentation

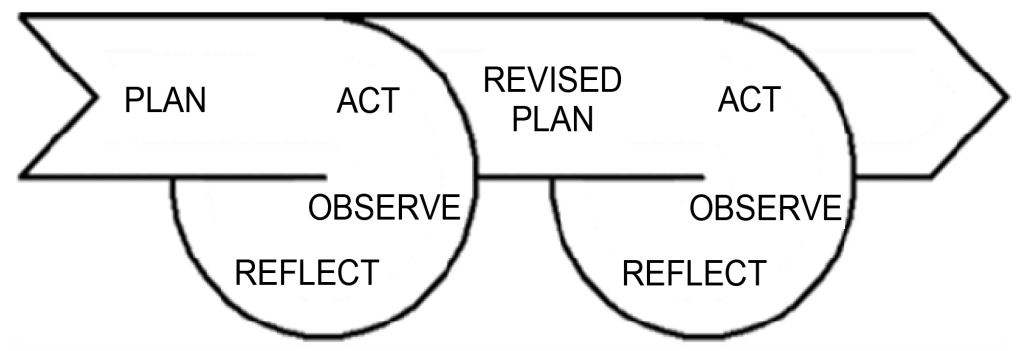

Figure 2. Action research cycle (Action Research Cycle, n.d.). 
which is a "Presentation software... and educational application" (Basturk, 2008: p. 432) and role play was used based on the topics selected by the researchers and the extent of coverage of these topics was guided by the pre-intervention data (Figure 3).

The powerpoint presentatione covered the topics what is bullying? people involved in bullying, types of bullying in schools, victims of bullying, perpetrators of bullying, causes of bullying in schools, effects of bullying on students, effects of bullying on teachers, strategies for addressing bullying in schools and what can I do about bullying in my school?

The action research cycle for this research consists of meeting the research participants, needs analysis, construction of powerpoint and other materials, implementation of the intervention and evaluation as demonstrated in Figure 4.

This research consists of one cycle because we meet with participants to sensitize them to the content, ethics and procedure of the research and their participation was solicited. A focus group discussion, conversational style interview was conducted and pre-intervention questionnaire was administered to determine the information that the research participants already have on bullying its impact and the strategies for addressing same. This allows for the planning of the relevant content to be desseminated and activities to be included in the intervention.

The powerpoint, materials including videos and activities for the workshop will be prepared being guided by the information collected from the needs analysis. The Workshop will then be implemented. An evaluation was followed

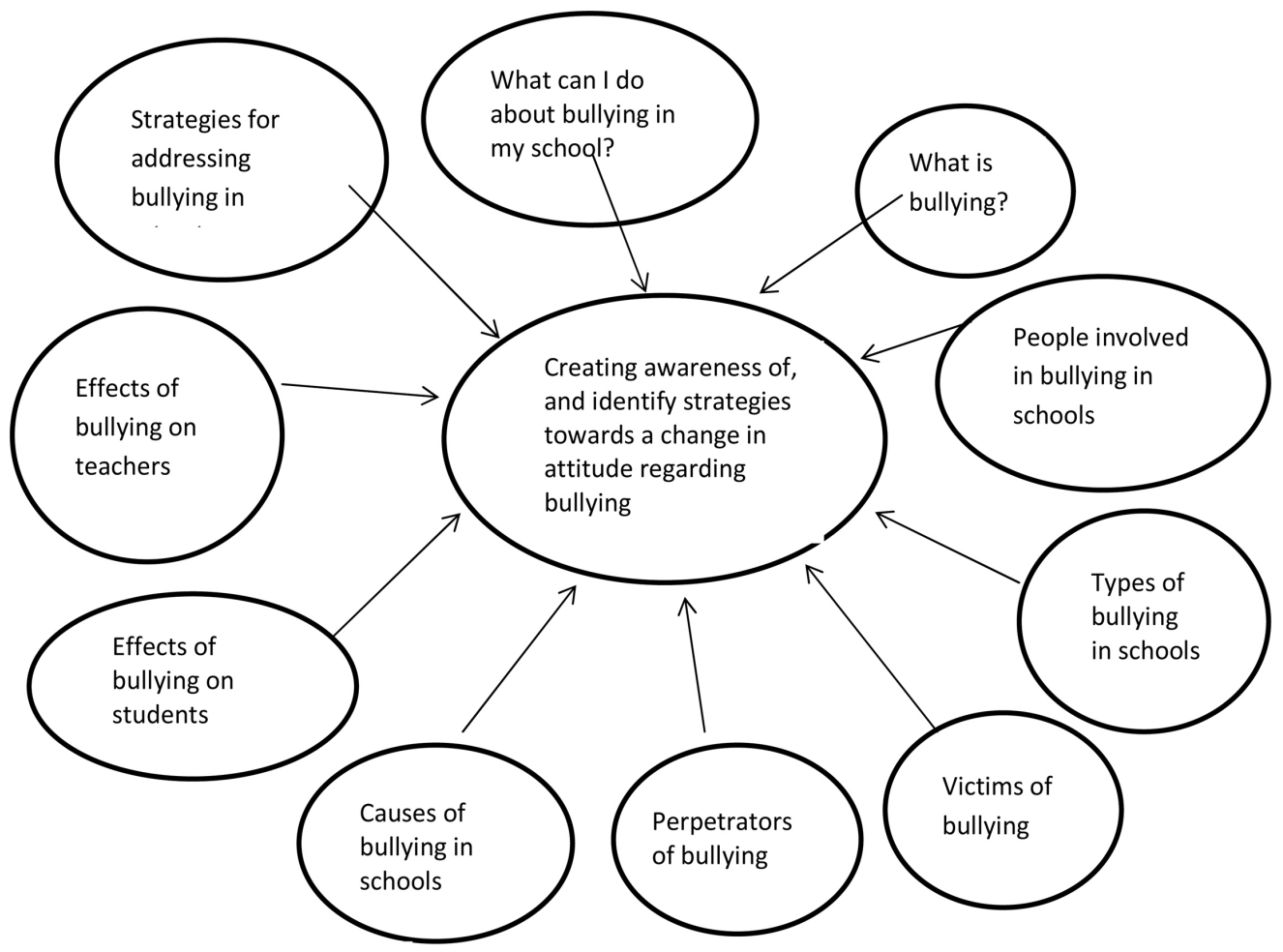

Figure 3. Powerpoint with topics. 


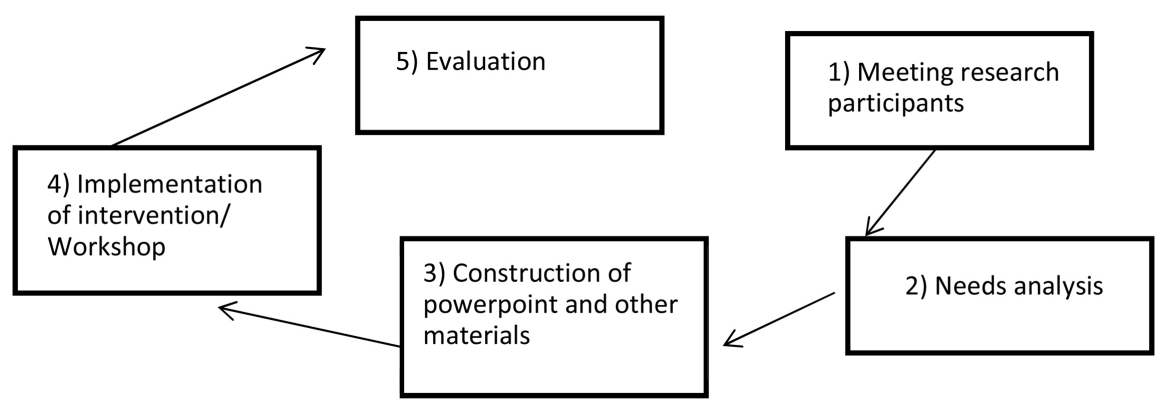

Figure 4. Action research cycle for this research.

through focus group discussion, role play, and post-intervention questionnaire to determine what happened (See Appendix C).

\subsection{Population and Sample}

The sampling of participants was done using purposeful random sampling by requesting 5 volunteers from each grade 7 class and 2 volunteers from the Guidance Counsellors. Purposeful random sampling is the process of identifying a population of interest and developing a systematic way of selecting cases not based on advanced knowledge of how the outcomes would appear. The aim of this type of selection is to increase credibility and not to promote representativeness (Lund Research Ltd., 2012). 20 letters with informed consent forms attached were given to one of the Guidance Counsellors for distribution to parents of the selected students seeking permission for their child to participate in the research. 5 signed copies were returned giving their child permission. The student participants signed the assent and the 2 Guidance Counsellor participants informed consent. The study was conducted with four grade 7 students, 2 aged 12 years and 2 aged 13 years in all-girls secondary school situated in the corporate area of Jamaica.

\subsection{Instrumentation}

The instruments utilized in data collection aiming to answer the research questions were questionnaires pre-intervention to determine prior knowledge on and experience with bullying and post-intervention to determine changes in attitude if any (Creswell, 2012).

The information collected from the pre and post-intervention questionnaires seeks to answer the question; how can workshops be used to create awareness on bullying among grades 7 students? The second question answered to what extent can intervention increase awareness and change in attitude and behaviour towards bullying? The student participants knowledge of bullying, its impact, strategies and their personal experience is important therefore a conversational style interview including nine open ended questions and a questionnaire consisting of fourteen open and closed ended questions were administered to answer the questions; how can workshops be used to create awareness on bullying among grades 7 students (see Appendix A and Appendix B). Questionnaire in- 
cluding fourteen open and closed questions was used to answer the question; to what extent can workshops increase awareness and change in attitude and behaviour towards bullying (see Appendix C)

\section{Focus Group}

A focus group is a study that "is a carefully planned series of discussions designed to obtain perceptions on a defined area of interest in a permissive, non-threatening environment" (Hennink, 2007: p. 6); it is "a discussion around a given topic between 6 to 12 participants, which is monitored, guided if necessary and recorded by the researcher. The distinguishing feature of focus groups is the explicit use of group interaction to produce data" (Bloor et al., 2002: p. 78). It involves persons who are pre-determined, with main purpose of identifying "a range of different views around the research topic, and to gain an understanding of the issues from the perspective of the participants themselves gaining responses from diverse persons within a single session than individual interviews which can provide valuable information for ... "behavioural research and needs assessment" (Hennink, 2007: p. 5). Although Hennink (2007) concurs with Bloor et al. (2002) on the recommended number of participants, this adjunct method can be used with four persons as executed in research conducted by Isaksen \& Gjengedal (2006). This method is most appropriate as this research seeks to identify the student participants varied perspectives and on bullying, its impact and strategies for addressing same.

\subsection{Data Collection}

The researchers who are outsiders executed the process over four days between June 10, 2016 and June 17, 2016. Prior to the field work a letter seeking permission was sent to the principal of the institution and verbal permission was granted. We met with the three Guidance Counsellors for the school, outlined the research purpose, procedure and possible benefit to the school also deliberated on the possible times and dates convenient to conduct the research more so because it was the final term in the academic school year and the student were preparing to sit their end of term examinations. Twenty (20) letters and parental informed consent were given to the guidance counsellors to be given to the selected students seeking their permission for their child's participation in the research.

The action research was conducted over one cycle. The cycle commenced with day 1 during which the researchers collected the informed consent from the Guidance Counsellors for the student participants, only five parents completed and returned the consent form, and from the 2 Guidance Counsellors who volunteered to participate in the research. A conversational style interview was conducted with the 2 Guidance Counsellors soliciting responses to their understanding of bullying, the prevalence and management of bullying within their school as well as their concerns as it relates to bullying. Day 2 began with the researchers explaining the research purpose, procedure and possible benefit to the 
students while emphasizing that even though their parents gave permission their participation is optional. All five agreed to participate, however only four signed the assent form and those were given an information sheet detailing pertinent information about the research. A questionnaire administered followed by focus group discussion stimulated by a conversational style interview was conducted seeking responses to their understanding of bullying, the prevalence and management of bullying within their school, their experience with and concerns about bullying. The workshop was conducted day 3 with a powerpoint presentation covering the topics what is bullying?, people involved in bullying, types of bullying in schools, victims of bullying, perpetrators of bullying, causes of bullying in schools, effects of bullying on students, effects of bullying on teachers, strategies for addressing bullying in schools and what can I do about bullying in my school? The researchers permitted an interactive session with the students asking questions throughout the presentation. Day 4 commenced with a review on the topics presented on Day 3, workshop during which two videos Ways to Stop Bullying and How to "Beat" Cyberbullies were shown and discussed. Focus group discussion on bullying, its impact on students, strategies that can be employed and whether or not their perception and attitude towards bullying changed. Role Play. 4 groups randomly selected two persons to a group with persons overlapping. Each group was required to create a scenario where someone was bullied and demonstrate selected strategies. The types of bullying selected were Verbal, Cyber, Physical, Isolation and the strategies "Use of silent treatment/ignore", "Tell an Adult", "Controlling Anger" and "Use of self esteem".

The researchers observed throughout the research process and took notes. The participants' responses to the conversational style interviews, and the focus groups discussions were audio recorded and transcribe with web based Transcribe, and Potplayer.

\subsection{Ethical Considerations}

According to Leedy and Ormrod (2014), there are four ethical issues in research. These are protection from harm, informed consent, right to privacy, and honesty. These ethical issues will be upheld by researcher.

To collect the data needed for the research, the researchers requested the permission from the principal who is the authoritative figure at the school to which the research was conducted (see Appendix D). Letters about the research and informed consent forms where sent to the parents requesting permission for child's participation (see Appendix E). The Guidance Counsellors were given informed consent (see Appendix F); the students information sheet pertainting to the research (see Appendix G) and an assent form them to complete should they agree to participate (see Appendix $\mathrm{H}$ ).

\section{Data Analysis}

It is an imperative that the researchers become familiar with the data by reading 
and reading it. The focus of the analysis was guided by the research questions, (1) how can workshops be used to create awareness on bullying among grade 7 students? (2) to what extent can workshops increase awareness and change in attitude and behaviour towards bullying? This provides focus for the analysis (Taylor-Powell \& Renner, 2003; Morrison, 2014).

The data was organized by questions, noting the participants' responses while identifying "consistencies and differences" followed by the exploration connections relationships between the questions (Taylor-Powell \& Renner, 2003: p. 2).

The data was organized into pre-set and emerging themes assigning codes to these themes after which the questions were coded respectively. The data was evaluated for relative importance and relationship between the different themes by asking the questions; "how do these relate? What data support this interpretation? And what other factors may be contributing?" (Taylor-Powell \& Renner, 2003: p. 5). The researchers will then use the themes and connections to explain the findings.

\subsection{Findings}

\subsubsection{Pre Intervention Interviews Conducted}

The questions utilized within the research covered the categories of Perception, Prevalence, Management and Concerns with pre-set and emerging themes pertaining to bullying, its impact on the students and strategies currently employed with the institution.

Data were collected from semi-structured interview, pre and post-intervention questionnaire, focus group discussions, role play and researchers' observations.

\subsubsection{Participants Perception of Bullying}

Both Guidance Counsellors A and B presented the view that bullying is an act that results in negative impact on both the offender and the victim which can impact the victim psychologically and behaviourally. The students view bullying as "when someone is being picked on for a difference that they may have".

\subsubsection{The Reason for Students Bullying Others}

Student 1 believes that children bully others because they feel insecure and they are experiencing a "phase in their lives", Student 2 believes it's because of their looks and weakness in different areas, Student 3 believes that they want to have "power and strength over others" and Student 4 believes that to get "what they want and make fun of" the victim.

\subsubsection{The Concentration of Bullying Victims}

Guidance Counsellor B believes that bullying is rampant within the institution across the different grade levels and ranks it at 7.5 on a scale of 1 to 10 with one being the lowest frequency and 10 being the highest frequency. The said Guidance Counsellor shared that students who are bullied are mostly from the lower socio-economic status. The students reported that students from upper school, that is grades 9 to 11 , bully the students from lower school that is grades 7 to 8 
also that the bullies come from both the "upper class" and "the garrison".

\subsubsection{Current Response of the Victims to Bullying at the School}

The student participants shared that some of the victims refuse to tell the teachers about being bullied because they feel that it would not be addressed judiciously.

\subsubsection{The Types of Bullying in the School}

Both Guidance Counsellor A and B believe that the main types of bullying present in their institution are cyberbullying using Facebook to intimidate, scandalize and slander other students as well as verbal bullying with students saying mean things about other students. The students also shared unanimously that Cyberbullying is the main type of bullying in their institution along with one student adding emotional bullying.

\subsubsection{The Impact of Bullying on Students within the School}

Counsellor B stated that some students who are bullied result in self-mutilation, mismanagement of their stressors and harm others through for example stabbing them. Both Guidance Counsellor A and B shared that when the girls are bullied they "cry, stay away from class and sometimes come up here (that is to the Guidance Counselling section) and they refuse to go back to their class and sometimes parents complain that they don't want to come to school because of what they are experiencing" Guidance Counsellor B shared that "the girls don't have the skills to cope with what they experience in terms of the circulation of rumours and other students trying to intimidate them...so they self-mutilate and engage in series of negative self-talk". All the students reported that they know persons who have been bullied. The students' who they witness being bullied in their class "get with withdrawn, cries and sometimes fight". When the students fight back the bully increases the intensity of bullying act. The students reported that when they are bullied or witness bullying they do not inform the teacher because in some cases the teacher does nothing; and that they fear being "beaten and called informer". They shared that some students travel with "knives and tools". They shared that some students have been ganged at the bus terminus by girls and their boyfriends from some of the renowned all-boys school. One of the students shared that she know of another student who was being bullied prior to attending that institution and when she is in class she doesn't talk to anyone she becomes withdrawn and is always "drawing" in class. Student 1 , shared that when she thinks of someone being bullied she cries because "it is very hard and because I wouldn't like that to happen to me".

\subsubsection{The Participants' Experiences}

All four students reported as having experienced being bullied. They all reported having experienced cyberbullying, additionally two students reported being verbally abused and one emotionally and physically abused as well. The students describe physical bullying as hitting, cyberbullying as "...posting things about 
me on the internet, social media, facebook", emotional bullying as saying "you are good for nothing, you are worthless, you are ugly" and relational bullying "...friend forcing another to do something that they don't want to do". When bullied Student 3 reported that she "walked away and tried to kill myself", student 4 reported, "I was tired of getting bullied so I stood up to her and talked it out but it didn't stop so we fought and I won". Student 2 shared that she experienced verbal bullying at the primary school that she attended. She shared that the bully operated within a group and that she tried to ignore the bully. Sometimes she didn't want to go to school, she cried, tried to commit suicide and at one point she planned to stab the bully. She said that "I take the chair and beat herr in her head because I was very tired".

\subsubsection{Treatment That Should Be Implemented}

The student participants believed that the victim should defend themselves, the offenders punished or charged as a criminal offense and should be reported to an adult.

They believed that the offenders should address their issues at home, a program should be created to prevent bullying and that the victims should select carefully their friends.

\subsubsection{Measures Implemented by the School to Address Bullying}

Guidance Counsellor A and B said that the school engage different entities to assist them in addressing the issues of bullying and other maladaptive behaviours. Because of the frequency of bullying, in summer of 2015 the school engaged the services of an institution to provide group counselling for selected students and they reported that they saw major changes with the girls who participated. It is their intention to send the current group of grade 7 to a similar programme this year. Guidance Counsellor B shared that a group of girls is preparing to launch an anti-bullying campaign. Guidance Counsellor A shared that the school currently includes anti-bullying lessons within their curriculum which is used across the different grade levels. The students are also engaged through discussions on the subject at the class level. They also have a "love yourself day" which is used to assist in building the student's morale. The student shared that the school implemented cameras to assist in addressing bullying.

\subsubsection{Other Interventions That Can Be Implemented to Address Bullying}

Guidance Counsellor B believe that despite the measure that the school currently have in place she would recommend workshops with the goal of assisting the students in understanding the impact of bullying on other students and strategies that they can use to manage effectively bullying. Guidance Counsellor B further recommended that the workshops could be conduct tri-monthly inclusive of students, teachers, dean of discipline, parents and administrative staff. While Guidance Counsellor A shared that concerned students believe that bullying is spiralling out of control and are desirous of working on implementing 
anti-bullying programmes.

\subsubsection{The Importance of Awareness of Bullying and Its Impact}

All student participants believe that it is important for them to be aware of bullying and its impact.

\subsubsection{Concerns That Participants Have about Bullying in Their School} Both Guidance Counsellor A and B expressed concerns about the psychological impact on the students who are bullied and the psychological state of the bully. Guidance Counsellor B is also concerned about whether or not the parent is aware of the damage that is done to the students who are bullied.

\subsubsection{Ways in Which the Participants' Thinking Have Changed about Bullying after the Workshop}

All the student participants reported that their thinking about bullying has changed positively after the workshop. The comments were that they now believe that the offender can see their error and conduct introspection towards change, bullying is now seen as very important and they now use empathy to understand the victim's experience also that they are now aware that victims may commit suicide or homicide.

\subsubsection{New Ways of Dealing with Bullying as a Victim}

If bullied now the student participants say they would tell an adult, ignore the bully, make a list of the positive qualities of self or call Child Development Agency.

\subsubsection{New Ways of Dealing with Bullying as an Observer}

If the student participants observed other girls being bullied they will now intervene and talk with both persons in particular the bully, encourage the victim to report it and discourage them from fighting, provide social and emotional support to the victim.

Student 1 believes that she could help by comforting the victim of bullying also reporting it to the school's authority.

\subsubsection{New Ways of Helping Their School to Address Bullying}

The student participants shared that they are now willing to as sit in addressing bullying by helping others to develop their self-esteem, by telling the other students in their class that bullying is wrong and by forming a club called "Stop Bullying and Speak Up".

\subsubsection{Recommendations for Addressing Bullying}

The student participants believed that bullying can be prevented by the bullies refraining from bullying and the erection of anti-bullying signs and posters on the campus (Table 1).

The students shared that they will take a more active role if they see others being bullied by encouraging the victim to report it and not fight back, provide emotional and social support for the victim, try to help both the perpetrator and 
Table 1. Showing pre-intervention and post-intervention.

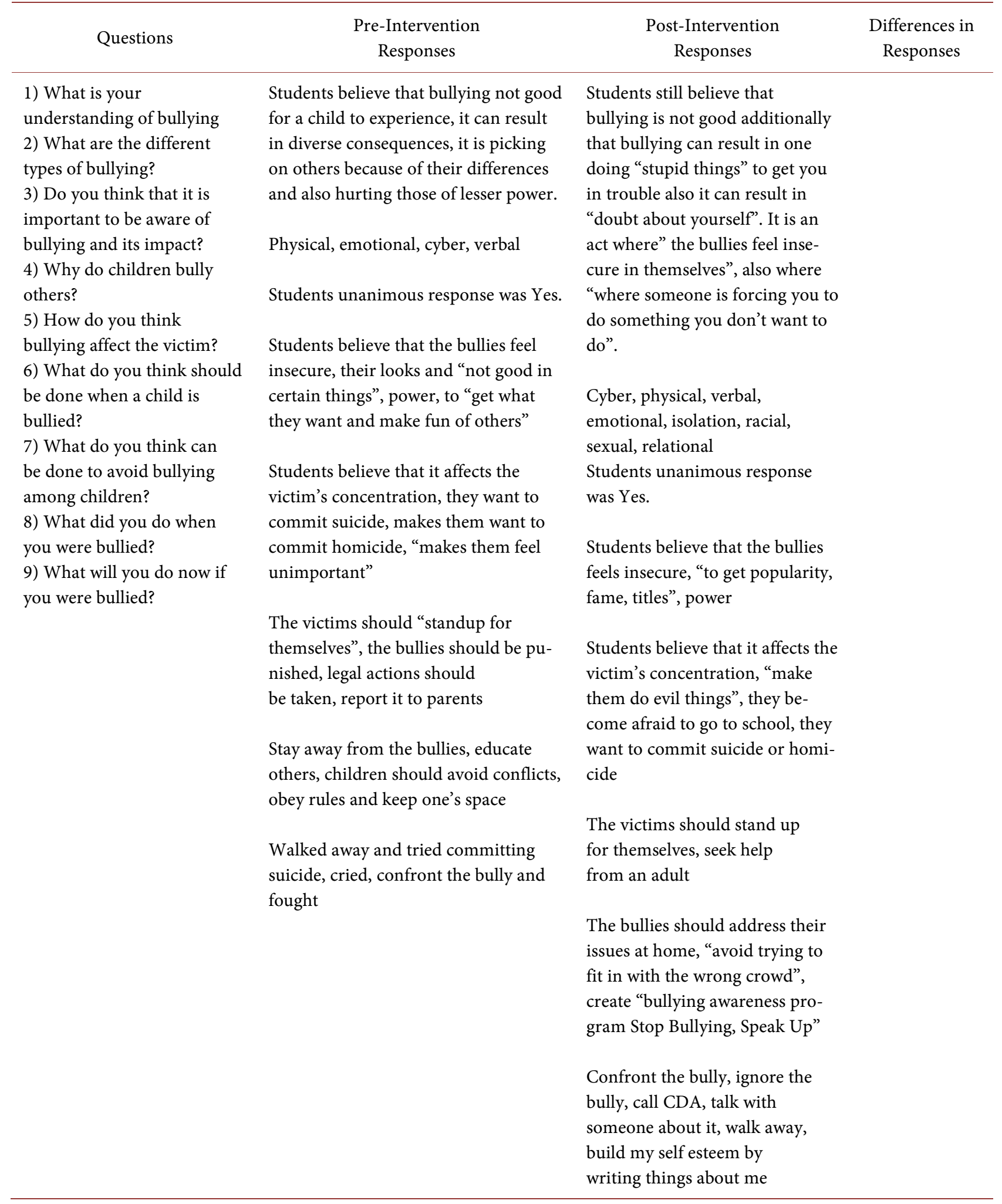

the victim by talking with then about bullying, its impact and the importance of discontinuing it. All the students reported that their thinking about bullying 
have changed after participating in the workshops. The students shared that "when I started doing the workshop I didn't think that bullying was so very important", "I... put myself in the victim's shoes, I have learnt that children commit suicide ... when they are bullied" and that they now learn that the bullies can see their mistakes and do self reflection.

The students shared that they can now help to prevent bullying at their school by helping the girls to believe in themselves, start bullying awareness campaign, make signs and posters about anti-bullying and educate other students in their class about bullying and "tell them it is not right".

\section{Discussions and Conclusions}

All the participants believe that bullying is an event that impact the victim negatively psychologically and emotionally, and where the offender seeks power and this perspective is corroborated by (Schneider et al., 2012; Side \& Johnson, 2014; Dunne et al., 2013; Gibson-Young et al., 2014; Arslan et al., 2012), and victims were different is reinforced by Thornberg (2015) and Side \& Johnson (2014). All the student participants reported that they have experienced bullying mostly physical, and the students and Guidance Counsellors shared that although physical, verbal, emotional and relational bullying exist within their school the main type experienced by students there is cyberbullying. All the participants believe that bullying is a problem within the school (PSearch Associates Company Ltd., 2015) and shared that the victims of bullying sometimes fight, gets withdrawn and self-mutilate and that the students in the upper grade bullies those in the lower grade and Schneider et al. (2012) revealed same.

This research seeks to answer the following research questions:

1) How can workshops be used to create awareness on bullying among grades 7 students?

2) To what extent can workshops increase awareness and change in attitude and behaviour towards bullying?

Prior to the intervention the students' thoughts revealed that bullying was wrong, there were consequences as a result, victims bullied for their differences and that the bully seeks power. They shared their knowledge of the types of bullying as physical, emotional and cyber and when they experienced bullying they either walked away, cried, confront the bully, tried to commit suicide or fought. Post intervention the modification is revealed in the thoughts that bullying can result in one doing "stupid things" to get you in trouble also it can result in "doubt about yourself". It is an act where "the bullies feel insecure in themselves"; in the types as isolation, racial, sexual, relational and new ways of dealing if they are bullied as ignore the bully, call CDA, talk with someone about it, walk away, build my self-esteem by writing things about me.

Seminal literature revealed that both Jerome Bruner's and Albert Ellis's contribution is relevant to this research in that Jerome Bruner, one of the proponents of Constructivism Theory contends that "learners construct new ideas or 
concepts based upon existing knowledge" (Bruner, 1960). The findings from the research illustrated that the students didn't have a "clear slate" about bullying its impact and strategies towards addressing same, however the information provided through the workshops provided the opportunity for them to increase their reservoir of knowledge on the subject. Albert Ellis the founder of one of the Cognitive Behavioural Theories, Rational Emotive Behavioural Theory argues that there is an event and persons have thoughts, feelings and behaviour as a result of that event. Where there is a change in thoughts there is a domino effect on the feelings and behaviour (Ellis and Dryden, 1997). Being guided by that theory the findings satisfied the goal of this research which is to create awareness of, and identify strategies towards a change in attitude regarding bullying, using workshops with grade seven students. Attitude as defined by the Merriam-Webster Dictionary (n.d.) is "a feeling or way of thinking that affects a person's behaviour" and there is evidence to suggest that the students' way of thinking about bullying and addressing same has changed. The seminal work of Ellis's theory informs that a change in thoughts produce a corresponding change in feelings and behaviour therefore it can be hypothesized that this positive change in thoughts that is evident among these student can yield a corresponding positive change in their feeling and behaviour that is, their attitude.

\subsection{Conclusion}

The research focused on creating awareness of, and identifying strategies towards a change in attitude regarding bullying, among grade 7 students at an all girls' school in Kingston, Jamaica. The findings revealed that there was an increase in knowledge among the students in the areas of their understanding of bullying, the reason behind children being bullied, the impact on the victim and strategies in addressing and preventing bullying.

Bullying has a negative impact on our schools' climate by infringing on the rights of students to learn in a safe and secure environment without fear from other students and even teachers. It has been noted that bullying has had a great impact on students' academic achievement, social interactions, and overall wellbeing (Kevorkian and D'Antona, 2008).

Within this study, participants not only drew from their own personal experiences, participants also revealed empathy for those who had been bullied of students after reflecting upon their own personal experiences. As always, with the previous statements on personal experiences and empathy, the school counsellors as part of the study reflected these students were their children and that they feel a connection with bullying that exceeded just compliance with policy. With this, a need was felt to protect these children through the promotion of a learning environment that is positive and safe.

It was submitted by the participants in this section that these experiences caused them to be more sensitive to the issue and the students. These experiences may have had effects on how the school management approached their 
current work on addressing student bullying. Feelings such as these have taken school officials beyond mere compliance with ministry of education policy and into a place of doing everything which they can do to help the students. This premise would inform the various aspects of the school management both teaching and non-teaching for professional development and training on how to deal with bullying.

\subsection{Recommendation}

These recommendations may be useful to all stakeholders in education:

1) Playground supervision should be monitored and that students be monitored within their classes, restrooms, the cafeteria and other areas which were noted in the school survey as hot spots for bullying.

2) Scheduling regular schoolwide assembles and teacher/staff development in order for them to raise awareness and communicate their policy of intolerance for students and staff who bully students.

3) Ensure a school rule entitled no teasing no put downs be established and enforced

4) Ensure a fool proof confidentiality system to report acts of bullying from both victims and witnesses where students may report acts of bullying without fear of retaliation.

5) Provide schoolwide co-curricular activities which are designed to build students' self-esteem e.g. talent showcasing, interest, hobbies and abilities.

6) Provide students with opportunities to discuss bullying and enlist their support in defining bullying as an unacceptable behavior. One way to begin a discussion is to conduct a session on current events with bullying as a topic. Students may share views and experiences.

7) Involve students in establishing classroom rules against bullying. Such rules may include a commitment from the teacher not to look the other way when bullying incidents occur.

8) Develop a classroom action plan so that students know what to do when they witness a bullying incident.

9) Take immediate action when bullying is observed or reported. By taking immediate action and dealing directly with the bully, adults support both the target and the witnesses.

10) Confront bullies in private. Engaging the bully in front of peers may enhance the bully's status and power or lead to further aggression.

11) Notify parents of both the bully and the target and try to resolve the problems as soon as possible, including referrals to counseling when appropriate.

12) Provide protection for students who may be targeted by bullies. One measure might include creating a buddy system to reduce the risk of attack or ridicule of the targeted student. Incorporate activities that foster mutual understanding and appreciation, such as research projects or invitations to guest speakers. 
13) Report bullying incidents you witness at school to an adult and encourage others to report bullying incidents and help them report if they cannot do it alone.

14) Support someone who has been hurt by offering kind words in private and helping them through the next steps.

Further research needs to be done on determining the etiology associated with the bully and how can family intervention assist in the prevention of bullying. Also effective strategies in addressing Cyberbullying within secondary schools especially in Jamaica.

\section{Conflicts of Interest}

The authors declare no conflicts of interest regarding the publication of this paper.

\section{References}

Action Research Cycle (n.d.). The Action Research Cycle.

Adeoye, A. (2013). The Moderating Effect of Home Setting and Religion Affiliation on the Effectiveness of Contingency Management and Cognitive Self Instruction on Bullying Behaviour of Secondary Students in Nigeria. IFE PsychologIA: An International Journal, 21, 250-257.

Allen, K. P. (2012). Off the Radar and Ubiquitous: Text Messaging and Its Relationship to "Drama" and Cyberbullying in an Affluent, Academically Rigorous US High School. Journal of Youth Studies, 15, 99-117. https://doi.org/10.1080/13676261.2011.630994

Arslan, S., Hallett, V., Akkas, E., \& Akkas, O. (2012). Bullying and Victimization among Turkish Children and Adolescents: Examining Prevalence and Associated Health Symptoms. European Journal of Pediatrics, 171, 1549-1557.

https://doi.org/10.1007/s00431-012-1782-9

Barnes, A., Cross, D., Lester, L., Hearn, L., Epstein, M., \& Monks, H. (2012). The Invisibility of Covert Bullying among Students: Challenges for School Intervention. Australian Journal of Guidance and Counselling, 22, 206-226. https://doi.org/10.1017/jgc.2012.27

Basturk, R. (2008). Applying the Many-Facet Rasch Model to Evaluate PowerPoint Presentation Performance in Higher Education. Assessment and Evaluation in Higher Education, 33, 431-444. https://doi.org/10.1080/02602930701562775

Bloor, M., Frankland, J., Thomas, M., \& Robson, K. (2002). Focus Groups in Social Research. Sage Publications Ltd. https://doi.org/10.4135/9781849209175

Bruner, J. (1960). Jerome Bruner (1915-) Constructivism and Discovery Learning.

Bruner, J. S. (2006). In Search of Pedagogy Volume 1: The Selected Works for Jerome $S$. Bruner. Routledge. https://doi.org/10.4324/9780203088609

Burns, A. (2010). Doing Action Research in English Language Teaching. Routledge. https://doi.org/10.4324/9780203863466

Child Development Agency (2015). Investigating the Prevalence and Impact of Peer Abuse on the Development of Jamaica Children.

Colibaba, S., Gavrila, C., Cleminte, A., Rotundu, E., \& Munteanu, N. (2012). Comprehension and Strategic Tackling of Bullying Phenomen in Schools (Case study: I Am Not Scared Project). Agronomy Series of Scientific Research, 55, 149-154. 
Creswell, J. W. (2012). Educational Research: Planning, Conducting and Evaluating quantitative and Qualitative Research. Pearson Education Inc.

Dunne, M., Sabates, R., Bosumtwi-Sam, C., \& Owusu, A. (2013). Peer Relations, Violence and School Attendance: Analyses of Bullying in Senior High Schools in Ghana. Journal of Development Studies, 49, 285-300. https://doi.org/10.1080/00220388.2012.671472

Ellis, A., \& Dryden, W. (1997). The Practice of Rational Emotive Behavior Therapy. Springer Publishing Company, Inc.

Gibson-Young, L., Martinasek, M. P., Clutter, M., \& Forrest, J. (2014). Are Students with Asthma at Increased Risk for Being a Victim of Bullying in School or Cyberspace? Findings from the 2011 Florida Youth Risk Behavior Survey. Journal of School Health, 84, 429-434. https://doi.org/10.1111/josh.12167

Grossi, P. K., \& Santos, A. M. (2012). Bullying in Brazilian Schools and Restorative Practices. Canadian Journal of Education, 35, 120-136.

Hemphill, S. A., Tollit, M., \& Kotevski, A. (2012). Rates of Bullying Perpetration and Victimization in a Longitudinal Study of Secondary School Students in Victoria, Australia Pastoral Care Education, 30, 99-112. https://doi.org/10.1080/02643944.2012.679953

Hennink, M. M. (2007). International Focus Group Research. Cambridge University Press. https://doi.org/10.1017/CBO9780511619458

Holt, M. K., Raczynski, K., Frey, K. S., Hymel, S., \& Limber, S. (2013). School and Community-Based Approaches for Preventing Bullying. Journal of School Violence, 12, 238-252. https://doi.org/10.1080/15388220.2013.792271

Huang, H., Hong, J., \& Espelage, D. (2013). Understanding Factors Associated with Bullying and Peer Victimization in Chinese Schools within Ecological Contexts. Journal of Child and Family Studies, 22, 881-892. https://doi.org/10.1007/s10826-012-9647-4

Hutchinson, M. (2012). Exploring the Impact of Bullying on Young Bystanders. Educational Psychology in Practice, 28, 425-442. https://doi.org/10.1080/02667363.2012.727785

Inhelder, B., \& Piaget, J. (1959). The Growth of Logical Thinking from Childhood to Adolescence. Basic Books Inc. https://doi.org/10.1037/10034-000

Isaksen, A. S., \& Gjengedal, E. (2006). The Significance of Fellow Patients for Patients with Myocardial Infection. Scandinavian Journal of Caring Science, 20, 403-411. https://doi.org/10.1111/j.1471-6712.2006.00421.x

Jones, J. R., \& Augustine, S. M. (2015). Creating an Anti-Bullying Culture in Secondary Schools: Characteristics to Consider When Constructing Appropriate Anti-Bullying Programs. American Secondary Education, 43, 73-83.

Kevorkian, M., \& D’Antona, R. (2008). 101 Facts about Bullying: What Everyone Should Know. Rowman \& Littlefield Education.

Leedy, P. D., \& Ormrod, J. E. (2014). Practical Research: Planning and Design (10th ed.). Pearson Education.

Lester, L., Cross, D., Shaw, T., \& Dooley, J. (2012). Adolescent Bully-Victims: Social Health and the Transition to Secondary School. Cambridge Journal of Education, 42, 213-233. https://doi.org/10.1080/0305764X.2012.676630

Lucassen, M., \& Burford, J. (2015). Educating for Diversity: An Evaluation of a Sexuality Diversity Workshop to Address Secondary School Bullying. Australasian Psychiatry, 23, 544-549. https://doi.org/10.1177/1039856215592324

Lund Research Ltd. (2012). Purposive Sampling.

http://dissertation.laerd.com/purposive-sampling.php 
Migliaccio, T., \& Raskauskas, J. (2013). Bullying as a Social Experience Social Factors, Prevention and Intervention.

Ministry of Education, Jamaica (2008). Security and Safety Policy Guidelines: Promoting a Culture of Security and Safety in Schools.

Mok, M., Wang, W., Chang, Y., Leung, S., \& Chen, L. (2014). Prevalence and Behavioral Ranking of Bullying and Victimization among Secondary Students in Hong Kong, Taiwan, and Macao. Asia-Pacific Education Researcher, 23, 757-767. https://doi.org/10.1007/s40299-013-0151-4

Morrison, B. K. (2014). Analyzing Qualitative Data: Quick Guide (pp. 1-3). Office of Assessment of Teaching \& Learning, Washington State University. https://atl.wsu.edu/documents/2015/03/qualitative-data-analysis.pdf

Murray-Harvey, R., Skrzypiec, G., \& Slee, P. T. (2012). Effective and Ineffective Coping with Bullying as Assessed by Informed Professionals and Their Use by Victimised Students. Australian Journal of Guidance and Counselling, 22, 122-138. https://doi.org/10.1017/jgc.2012.5

Ockerman, M., Kramer, C., \& Bruno, M. (2014). A Pilot Study of Bullying Behaviours among Middle School Students. Research in Middle Level Education Online, 37, 1-18. https://doi.org/10.1080/19404476.2014.11462109

Perkins, W. H., Perkins, J. M., \& Craig, D. (2014). No Safe Haven: Locations of Harassment and Bullying Victimization in Middle Schools. Journal of School Health, 84, 810-818. https://doi.org/10.1111/josh.12208

PSearch Associates Company Ltd. (2015). Investigating the Prevalence and Impact of Peer Abuse (Bullying) on the Development of Jamaica's Children. http://www.cda.gov.jm/wp-content/uploads/bullying_summary_FINAL.pdf

Pugh, R., \& Chitiyo, M. (2012). The Problem of Bullying in Schools and the Promise of Positive Behaviour Supports. Journal of Research in Special Educational Needs, 12, 47-53. https://doi.org/10.1111/j.1471-3802.2011.01204.x

Rigby, K. (2014). How Teachers Address Cases of Bullying in Schools: A Comparison of Five Reactive Approaches. Educational Psychology in Practice, 30, 409-419. https://doi.org/10.1080/02667363.2014.949629

Roberge, G. D. (2012). From Zero Tolerance to Early Intervention: The Evolution of School Anti-Bullying Policy. JEP: eJournal of Education Policy.

Santrock, J. W. (2002). Life-Span Development. McGraw-Hill.

Schneider, S. K., O’Donnell, L., Stueve, A., \& Coulter, R. W. (2012). Cyberbullying, School Bullying, and Psychological Distress: A Regional Census of High School Students. American Journal of Public Health, 102, 171-177. https://doi.org/10.2105/AJPH.2011.300308

Side, J., \& Johnson, K. (2014). Bullying in Schools: Why It Happens, How It Makes Young People Feel and What We Can Do about It. Educational Psychological in Practice, 30, 217-231. https://doi.org/10.1080/02667363.2014.915209

Smith, P., Kupferberg, J. A., Mora-Merchan, M. S., Bosley, S., \& Osborn, R. (2012). A Content Analysis of School Anti-Bullying Policies: A Follow-Up after Six Years. Educational Psychology Practice, 28, 47-70. https://doi.org/10.1080/02667363.2011.639344

Smith, P., Smith, P. K., \& Blumberg, H. (2010). Addressing Cyberbullying in School Using Quality Circle Approach. Australian Journal of Guidance Counselling, 20, 157-168. https://doi.org/10.1375/ajgc.20.2.157

Smith, R. W., \& Smith, K. (2014). Creating the Cougar Watch: Learning to Be Proactive against Bullying in Schools. Middle School Journal, 46, 13-19. 


\section{https://doi.org/10.1080/00940771.2014.11461900}

Srabstein, J., \& Leventhal, B. (2010). Prevention of Bullying-Related Morbidity and Mortality: A Call for Public Health Policies. Bulletin of the World Health Organization, 88, 403. https://doi.org/10.2471/BLT.10.077123

Stauffer, S., Heath, M. A., Coyne, M. S., \& Ferrin, S. (2012). High School Teachers' Perceptions of Cyberbullying Prevention and Intervention Strategies. Psychology in the Schools, 49, 353-367. https://doi.org/10.1002/pits.21603

Steinert, Y., \& Ouellet, M. N. (2012). Designing Successful Workshops. McGill University.

Stopbullying.gov (n.d). What Is Bullying? https://www.stopbullying.gov/

Taylor-Powell, E., \& Renner, M. (2003). Analyzing Quantitative Data (pp. 1-10). University of Wisconsin-Extension. http://learningstore.uwex.edu/assets/pdfs/g3658-12.pdf

Thornberg, R. (2015). Distressed Bullies, Social Positioning and Odd Victims: Young People's Explanations of Bullying. Children and Society, 29, 15-25. https://doi.org/10.1111/chso.12015

Wurf, G. (2012). High School Anti-Bullying Interventions: An Evaluation of Curriculum Approaches and the Method of Hared Concern in Four Hong Kong International Schools. Australian Journal of Guidance and Counselling, 22, 139-149. https://doi.org/10.1017/jgc.2012.2

Yerlikaya, I. (2014). Evaluation of Bullying Events among Secondary Education Students in Terms of School Type, Gender and Class Level. International Journal of Progressive Education, 23, 757-767. 


\section{Appendix A}

\section{Students' Questionnaire \\ Prior Knowledge and Experience on Bullying}

Title of Project: Creatingawareness of bullying, its impact on children, and strategies towards behavioural change

Researchers: Angela Daniels and Wasiu Abayomi, doctoral student of the International University of the Caribbean

Purpose: The purpose of this research is to create awareness of, and identify strategies towards a change in attitude regarding bullying, among grade seven students

Instructions: Complete each question accordingly

1) What is your understanding of bullying?

2) What are the different types of bullying?

3) Do you think that it is important to be aware of bullying and its impact? 0 Yes $\circ$ No

4) No child should be bullied. $\odot$ Strongly Agree $\circ$ Agree $\odot$ Disagree $\circ$ Strongly Disagree

5) How old are you?

6) Why do children bully others?

7) How do you think bullying affect the victim?

8) What do you think should be done when a child is bullied?

9) What do you think can be done to avoid bullying among children?

10) Do you bully other children? ○ Yes $\circ$ No

11) Have you ever been bullied? $\circ$ Yes $\circ$ No

12) What type of bullying did you experience?

13) What did you do when you were bullied?

14) Please add any other comments on how you can prevent bullying.

The information that you provide with be used solely for the stated purpose, and your identity will be protected.

Thank you for your participation.

Adapted Burns (2010).

\section{Appendix B}

Creating awareness of Bullying, its Impact on Children, and Strategies towards Behavioural change

Conversational Interview Questions

Principal, Guidance Counsellor and Students

Pre-intervention Data

Date.

1) Prevalence

a) What is your perception of bullying? 
b) To what extent is bullying present within this school?

c) Is bullying more prevalent among specific grades and economic status?

d) What types of bullying have you seen within this school?

e) What impact does bullying have on your students?

2) Management

a) What measures has the school implemented in addressing the issue of bullying?

b) What other interventions do you think that you can implement in addressing the issue of bullying?

\section{3) Concerns}

a) What concerns do you have about bullying in your school?

b) What are your recommendations for the treatment and prevention of bullying?

\section{Appendix C}

\section{Students' Questionnaire \\ Post Workshop}

Title of Project: Creating awareness of bullying, its impact on children, and strategies towards behavioural change.

Researchers: Angela Daniels and Wasiu Abayomi, doctoral student of the International University of the Caribbean.

Purpose: The purpose of this research is to create awareness of, and identify strategies towards a change in attitude regarding bullying, among grade seven students.

Instructions: Complete each question accordingly

1) What is your understanding of bullying?

2) What are the different types of bullying?

3) Do you think that it is important to be aware of bullying and its impact? 0 Yes $\circ$ No

4) No child should be bullied. $\odot$ Strongly Agree $\odot$ Agree $\odot$ Disagree $\odot$ Strongly Disagree

5) How old are you?

6) Why do children bully others?

7) How do you think bullying affect the victim?

8) What do you think should be done when a child is bullied?

9) What do you think can be done to avoid bullying among children?

10) What will you do now, if you were bullied?

11) What will you do now, if you see someone being bullied?

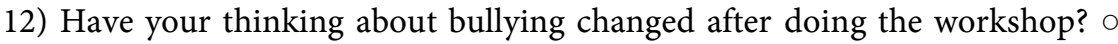
Yes $\circ$ No

12a) If yes, how has it been changed? 
12b) If no, why it has not been changed?

13) What will you now do to help prevent bullying in your school?

14) Please add any other comments on how you can prevent bullying.

The information that you provide with be used solely for the stated purpose, and your identity will be protected.

Thank you for your participation.

Adapted Burns (2010).

\section{Appendix D}

May 17, 2016

The Principal

(School's Address)

Re: Permission to conduct Action Research at (School's Name)

Dear ...........,

We are Angela Daniels and Wasiu Abayomi students of the International University of the Caribbean who are pursuing studies in the Doctor of Education programme. One of the requirements of this programme is to conduct an Action Research.

The goal of this research is to createawareness of bullying, its impact on children, and strategies towards behavioural change, among secondary level students. The focus of this research is to create awareness of, and identify strategies towards a change in attitude regarding bullying, among grade seven students. An increase in awareness can result in behavioural and attitudinal changes within the students who participate in this research and by extension, over time, within the overall student population.

The research will be conducted with twenty (20) students from grade 7 who will be selected through Simple Random Sampling. The data will be collected through conversational interviews where the responses will be recorded using a mobile telephone and; questionnaires. Your students will be requested to participate in focus group discussions and workshops. The focus groups will be conducted at the commencement and conclusion of the research, and the workshops preferably at the end of the school day (Mondays, Wednesdays and Fridays) over a two week period. The intended dates are June 6, 8, 10, 13, 15 and 17, 2016. The duration of each session will be one and a half hours. These discussions will be recorded using a mobile telephone. Data will be collected from The Principal, the Guidance Counsellor for Lower School and student participants through conversational interviews prior to the intervention in order to assist in guiding the planning for intervention. Subsequent to the action cycles an evaluation will be conducted to determine changes in awareness, attitudes and behaviours if any.

Permission will be procured from: 
1) the Principal for access to the institution and participation in the interview,

2) the Guidance Counsellor from Lower School,

3) the parents for their child's participation and

4) from the child participant agreeing to participate

All data will be treated under confidential cover ensuring anonymity. The data collected will be securely stored in a locked cabinet. Although there is minimal risk to the participants, care will be taken to address any psychological or emotional distress observed as a result of questions asked. Your students may benefit directly from the process. Your students' participation is voluntary, and they are free to terminate without providing a reason at any time throughout the research process without prejudice, and the data collected will be destroyed. The report will belong to the International University of the Caribbean; however, a copy will be submitted to the school for informational purposes.

If you have any complaints or reservations about any ethical aspect of your participation in this research, you may contact Dr. Allison Harrisingh-Tucker at the International University of the Caribbean (Telephone: 876754 8727). Any complaint you make will be treated in confidence and investigated, and you will be informed of the outcome. Should you have any questions concerning this research you can contact Angela Daniels at (876) 315-7075 or Wasiu Abayomi at (876) 868-1165.

We request your permission to share the findings from this research in peer reviewed journals and at the International University of the Caribbean academic conferences. We will ensure that neither you nor your institution will be identified. No reference to personal names will be used. The data collected will be governed by the ethical provision stated earlier.

I have understood the contents of this Informed Consent and agree to participate in this research. I have also received a signed copy.

Signature of Participant Date

Researcher's Signature Date

Researcher's Signature Date

Witness Signature Date

\section{Appendix E}

\section{INTERNATIONAL UNIVERSITY OF THE CARIBBEAN}

47 Old Hope Rd, Kingston, Jamaica

June 6, 2016

Dear Parent/Guardian:

We are seeking your permission for your child to participate in research on Creating Awareness of Bullying, its Impact on Children and Strategies towards 
Behavioural Change. This study will be a series of workshops that will be conducted at the Merl Grove High School over a two (2) week period 1 1/2 hours for each session, immediately after school on Monday, Wednesday and Friday during the period June 8 to 20, 2016.

We are interested in knowing if Creating Awareness of Bullying, its Impact on Children and Strategies, among grade seven students can result in a change in attitude. This research can assist us in finding another successful approach which, when employed may result in the reduction in the frequency of school based violence. The workshops will include information, strategies and activities that your child will participate in and when the knowledge is applied can result is a positive approach to bullying.

We invite your child to participate in this research; however, your child's participation is dependent on you granting permission. We will ask your child to participate in focus groups and workshops. All data collected will be confidential, your child's name will not be on any of the papers and only the researchers will know the participants in the study. Although there is minimal risk involved, care will be taken to address any psychological or emotional distress observed as a result of questions asked.

The research will be conducted among grade 7 students only, and will involve only those students whose parents grant permission for their participation. Should you desire to withdraw your child from this research you can do so at any time throughout the process without prejudice.

If you have any questions about your child's participation in this research, you may contact Dr. Allison Harrisingh-Tucker at the International University of the Caribbean (Telephone: 876754 8727).

Your child's participation will be greatly appreciated as the findings from this research can assist in reducing the frequency of bullying among grade seven students and by extension may assist is reducing school violence. Kindly complete the attached form and return it to the school by June 7, 2016. Should you have any questions concerning this research, please contact Angela Daniels at (876) 315-7075 or Wasiu Abayomi at (876) 868-1165. We thank you for your support of this research.

Yours sincerely,

Angela Daniels

(Researcher)

Wasiu Abayomi

(Researcher)

INFORMED CONSENT FOR YOUR CHILD

I acknowledge that I have read and understood the contents pertaining to the research with title Creating Awareness of Bullying, its Impact on Children and Strategies towards Behavioural Change, which will be conducted by Angela Da- 
niels and Wasiu Abayomi of the Department of Education, at the International University of the Caribbean.

I understand that the data collected will be kept confidential and that the information acquired from this research will be utilized solely for research purposes. I am fully aware that II can withdraw my child by informing the researchers at any time throughout the research process without prejudice.

I am aware that, should I have concerns and or reservations I can contact Angela Daniels at (876) 315-7075 or Wasiu Abayomi at (876) 868-1165.

- Yes-I agree for my child to participate in this research

$\circ$ No-I do not agree for my child to participate in this research.

Child's Name (please print)

Child's Age Gender of Child Male

Female

Parent or Guardian Signature Date

Researcher's Signature Date

Researcher's Title Department

Researcher's Signature Date

Researcher's Title Department

(Adapted from Immaculata University, n.d.)

\section{Appendix F}

\section{Name of institution:}

Action Research Informed Consent for Guidance Counsellor Lower School

Title of Research: Creating Awareness of Bullying, its Impact on Children, and Strategies towards Behavioural change

Angela Daniels and Wasiu Abayomi of the International University of the Caribbean are pursuing studies in the Doctor of Education programme. One of the requirements is to complete an Action Research.

The goal of this research is to create awareness of bullying, its impact on children, and strategies towards behavioural change, among secondary level students. The focus of this research is to create awareness of, and identify strategies towards a change in attitude regarding bullying, among grade seven students. An increase in awareness can result in behavioural and attitudinal changes within the students who participate in this research and by extension, over time, within the overall student population.

If you agree to participate in this interview, you will be asked nine open ended questions. Your responses will be audio-recorded. These recordings and the notes we take during the interview will be used as information for the action research.

Your participation in this research is voluntary and you can withdraw at any time. You do not have to give a reason for withdrawing from this research and 
there will be no negative consequences if you decide to withdraw.

We request your permission to share the findings from this interview. We will ensure that you are not identified. No reference to personal names will be used. We will be the only persons who will have access to the data collected for the research. The data will be used for the stated purpose.

\section{Participant Consent}

The participant has been given a signed copy of this form to keep.

I agree to participate in this project.

Signed: Date:

If you have any complaints or reservations about any ethical aspect of your participation in this project, you may contact Dr. Harrisingh-Tucker, the International University of the Caribbean (Telephone: 8767548727). Any complaint you make will be treated in confidence and investigated, and you will be informed of the outcome. Should you have any questions concerning this research you can contact Angela Daniels at (876) 315-7075 or Wasiu Abayomi at (876) 868-1165.

Name of Researcher: Date:

Name of Researcher: Date:

\section{Appendix G}

\section{INTERNATIONAL UNIVERSITY OF THE CARIBBEAN}

\section{Students' Information Sheet}

Study title: Creating Awareness of Bullying, its Impact on Children and Strategies towards

Behavioural Change.

Researchers: Angela Daniels and Wasiu Abayomi

\section{Why you are here?}

We would like for you to participate in focus groups and workshops where we listen to your perspectives on bullying and your experience with bullying. We would also like to share with you information and strategies about managing successfully bullying. You will also get the opportunity to demonstrate some of the strategies. We would like to know if you would be interested in this study. If you have questions you can ask the researchers or your parent/guardian.

Why are we doing this study? We would like to assist adolescents in managing better bullying. We want to know what strategies will work in successfully addressing bullying. We want to know if creating awareness of bullying and implementing these strategies can bring about a change in attitude and behavior.

How will we conduct the study? (If you want to be in the study these things will happen)

1) You will be asked to participate in focus group before the workshop where we will collect information on your current knowledge on bullying and strategies used by students and teachers at your school.

2) The workshops will include information on the types and impact of bully- 
ing on children, different things that children can do if they are bullied or witness bullying and approaches that can be used to prevent bullying. You will also be asked to participate in role plays.

3) After the workshops you will be asked to participate in focus group to determine the changes that might have occurred pertaining to awareness, impact and strategies

4) The study will last for about 6 days (Monday, Wednesday and Friday) over 2 weeks. You will be asked to meet after school for $11 / 2$ hours for each session

5) You will be asked to participate in conversational interviews and the responses will be recorded using a mobile telephone; complete questionnaires asking for your thoughts, feelings and experiences of bullying and focus group discussions. These discussions will be recorded using a mobile telephone.

Will this help you? This study may help you to be more aware of the bullying, its impact and the strategies that you can use in dealing with it. The information may assist you in changing your attitude and behavior about bullying. It may also help us to find another way in creating awareness on bullying among children in grade 7 . We hope that this study will help you to have a positive change in your attitude and behaviour pertaining to bullying, and that you will share with others the effective ways in which they can deal with bullying.

\section{Appendix $\mathrm{H}$}

\section{INTERNATIONAL UNIVERSITY OF THE CARIBBEAN}

Study title: Creating Awareness of Bullying, its Impact on Children and Strategies towards

Behavioural Change.

Researchers: Angela Daniels and Wasiu Abayomi

Why you are here? We would like for you to participate in focus groups and workshops where we listen to your perspectives and experiences on bullying. We would also like to share with you information and strategies about managing successfully bullying. We would like to know if you would be interested in this study. If you have questions you can ask the researchers or your parent/guardian.

Why are we doing this study? We would like to assist adolescents in managing better bullying. We want to know what strategies will work in successfully addressing bullying. We want to know if creating awareness of bullying and implementing these strategies can bring about a change in attitude.

How will we conduct the study? (If you want to be in the study these things will happen)

1) You will be asked to participate in focus group before and after the workshop.

2) The study will last for about 6 days (Monday, Wednesday and Friday) over 2 weeks.

3) You will be asked to participate in conversational interviews, role plays, complete questionnaires and focus group discussions. Both the responses to the 
interviews and focus group discussions will be recorded using a mobile telephone.

Will the study hurt? You may feel a little uncomfortable answering some of the questions, if that happen tell the researchers; we will also be observing and will take care in addressing anything that may disturb you.

Will this help you? This study may help you to be more aware of the bullying, its impact and the strategies that you can use in dealing with it. We hope that this study will help you to have a positive change in your attitude and behavour pertaining to bullying.

What if you have any questions? If you have any questions concerning this research please contact Angela Daniels at (876) 315-7075 or Wasiu Abayomi at (876) 868-1165.

Who will know what I did in the study? All data collected will be confidential, your name will not be on any of the papers and it is only the researchers will know who participated in the study.

Do I have to be in the study? You do not have to be in the study. If you agree to be in the study and change your mind, you can say so and terminate at any time without giving any reason and the papers collected from you will be destroyed. We will get permission from your parents to participate in this study.

Assent-Consent (written assent if you choose to sign the assent)

I agree to take part in this study and I am aware that I can change my mind and terminate at any time.

Print name of child Date of Birth

Signature of Child Date.

We verify that we have explained the contents of the study to the participant age appropriately, and that the participant has freely agreed to participate in the research.

\begin{tabular}{lll} 
Printed name of & \multicolumn{1}{c}{$\begin{array}{l}\text { Signature of } \\
\text { Person obtaining assent }\end{array}$} \\
Printed name of & Signature of & Date \\
Person obtaining assent & Person obtaining assent
\end{tabular}

(Adapted from the University of Manitoba Bannatyne Campus REB, 2004) 